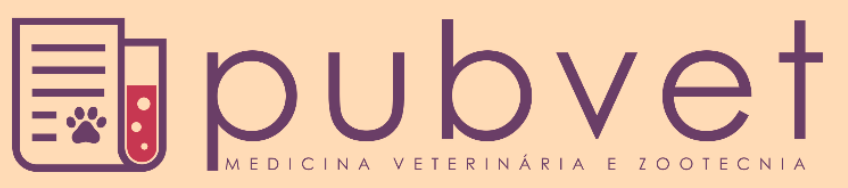

https://doi.org/10.31533/pubvet.v15n12a999.1-11

\title{
Importância do zoológico na conservação das espécies
}

\author{
Leticia Cacho Pimenta Pereira ${ }^{1}$, Luana Bernardo da Silva ${ }^{1}$, Gabriela Peres Abrantes ${ }^{*}$, \\ Lorella Xavier $^{1 \oplus \text {, Rafaela Pereira Nunes }}{ }^{1 \oplus}$, Anderson Scherer ${ }^{2} \oplus$ \\ ${ }^{1}$ Graduanda em Medicina Veterinária na Universidade Anhembi Morumbi, São Paulo - SP \\ ${ }^{2}$ Professor na Universidade Anhembi Morumbi no departamento de Projetos integração saúde e comunidade, São Paulo - SP \\ *Autor para correspondência, e-mail: bibi.abrantes@uol.com.br
}

Resumo. Com o aumento da preocupação com o Bem-estar animal, a população tende a pensar que o zoológico é somente um lugar de confinamento ou entretenimento, que não permite a livre expressão dos animais, porém o mesmo tem grande importância na conservação das espécies ameaçadas de extinção, no resgate de animais debilitados ou que não podem retornar à natureza, e na reabilitação e soltura daqueles seres que podem. Em outras palavras, a concepção sobre a intenção real do zoológico vem apresentando mudanças: antigamente, servia como um menagerie imperial, onde os imperadores usavam esses animais em jogos realizados em uma arena como forma de entretenimento do público. Hoje, no entanto, este recinto foi adaptado para contribuir econômica, ambiental e turisticamente com diversos papéis importantes como a conservação das diversas espécies existentes, contribuição com a importância científica, possibilitando técnicas de conservação (in situ e ex situ), promoção do enriquecimento e a educação ambiental, e tornando possível a reabilitação e a soltura dos animais aptos para retornarem à vida livre. O presente estudo buscou ressaltar a importância do zoológico na conservação das espécies, incluindo abordar sobre aquelas que já foram extintas e as que estão ameaçadas de extinção no Brasil, fornecendo um panorama geral sobre zoológicos e suas atuais funções.

Palavras-chave: Bem-estar animal, conservação, educação ambiental, espécies, extinção, zoológico

\section{Importance of the zoo in the conservation of species}

Abstract. With the rising worries about animal welfare, the population tends to think that the zoo is a place of confinement and entertainment that doesn't allow the free will of animals. Nevertheless, it has a big importance in the conservation of endangered species, rescue of impaired animals or the ones that cannot return to nature, rehabilitation and release of the ones that can. In other words, the conception of the real intentions of the zoo have been presenting changes: formerly, it served as an imperial menagerie, where the emperors used the animals in games at an arena as a way of public amusement. Nowadays, however, it has adapted to contribute economically, environmentally and touristic with many important roles such as conservation of numerous existing species, scientific contribution, enabling conservation techniques (In Situ and Ex situ), promotion of ambiental enrichment and education, and making it possible to rehabilitate and release animals that are fit to rejoint their free lives. The present study intends to highlight the importance of the zoo in the conservation of species, including the approach of the ones that are already extinct and the ones endangered in Brazil, providing a general outlook about zoos and their current purpose.

Keywords: Ambiental education, animal welfare, conservation, extinction, species, zoo 


\section{Introdução}

Historicamente, em 1750, já existia uma visão prévia do primeiro e mais antigo zoológico do mundo, situado no Palácio de Schönbrunn em Viena, na Áustria. A ideia inicial seria a criação de um menagerie (Zoológico imperial). Apenas em 1882, o primeiro zoológico brasileiro foi inaugurado, sendo um anexo ao Museu Paraense Emílio Goeldi, em Belém do Pará e, atualmente, ele é um dos principais centros de pesquisa no país e referência internacional (Sanjad et al., 2012). De acordo com a Sociedade Brasileira de Zoológicos e Aquários do Brasil, os zoológicos devem promover a educação ambiental, bem como a conservação ex-situ dos componentes da fauna, nos precisos termos da Lei no 9.795/99, em consonância com os princípios constitucionais previstos no Art. 225 da Constituição da República Federativa do Brasil de 5 de outubro de 1988. Nisso, vale lembrar que os programas de conservação não envolvem somente a reprodução das espécies ameaçadas. Marino (2008) diz que o mais importante é o impacto que essas instituições produzem sobre o público, responsável por influenciar tomadas de decisões que definem o êxito ou o fracasso das políticas públicas conservacionistas. Prova disso é que a visitação estimada em cerca de 30 milhões de visitantes por ano demonstra também a importância destas instituições como centros de educação ambiental para a população, aumentando o interesse, cuidado e conhecimento sobre a fauna silvestre. Entretanto, o zoológico ainda tem como um dos principais objetivos a exposição de animais como forma de entretenimento e diversão para o público, a fim de arrecadar verba e assim desenvolver atividades para outra missão: a conservação.

Assim, este trabalho tem como objetivo relatar a importância do zoológico na conservação das diversas espécies, incluindo suas outras funções primordiais como a importância científica, técnicas de conservação (in situlex situ), enriquecimento e educação ambiental, reabilitação e soltura dos animais; abordar sobre as espécies já extintas e as que estão ameaçadas de extinção no Brasil; aspecto geral sobre zoológicos brasileiros e estrangeiros e quando o zoo é privado ou público.

\section{Histórico}

Inicialmente, o zoológico era centrado em torno de um pavilhão destinado para os cafés da manhã imperiais, onde havia 13 compartimentos para animais, sob a forma de pedaços de bolo, que se estabeleciam em torno deste pavilhão central. Tal modelo seguia o exemplo da menagerie do Palácio de Versailles na França (Dias, 2003). Em 1779 esse estabelecimento foi aberto ao público, apenas para as pessoas consideradas bem-vestidas. Um ano depois, os primeiros ursos polares, grandes felinos, hienas e cangurus, além de um par de elefantes indianos, chegaram a Schönbrunn, na Áustria, já que os animais exóticos atraíam as multidões, incluindo nativos e estrangeiros. No final do século XIX, o zoológico se tornou um ambiente mais amigável e humano para os animais, onde eliminou-se muitos muros e grades substituindo por cercados amplos. Desde então foram construídos lugares assim ao redor do mundo com o objetivo inicial de atender exclusivamente as necessidades de seus visitantes.

Hoje os zoológicos contam com quatro papéis fundamentais: educação, conservação, pesquisa e lazer, com perfil bastante diferenciado. De acordo com a União Internacional de Diretores de Jardins Zoológicos (IUDZG) (1993), três são os objetivos que devem servir de base para que um zoológico alcance as metas para as práticas conservacionistas: apoiar ativamente a conservação das populações ameaçadas de extinção, oferecer apoio e facilidades para pesquisas científicas e promover um aumento da sensibilização do público por questões voltadas para a conservação ambiental com a criação de políticas de educação ambiental (Maués \& Maline, 2019).

Pensando no aspecto de bem-estar animal do qual o zoológico também contribui, a visão social pelas questões voltadas ao meio ambiente vem propiciando mudanças significativas na forma como o ser humano se relaciona com os seres não humanos. O reconhecimento da cognição dos animais retira-os da condição de objetos de um meio, para sujeitos do mesmo, onde diversos aspectos complexos da interação animal-homem-meio passam a ser rediscutidas e reelaboradas (Almeida et al., 2010). Na medida em que esta perspectiva se difunde globalmente através dos meios científicos e zootécnicos, ela pode criar uma sobreposição de crenças tradicionais e dar um novo impulso para a consideração do bemestar dos animais. Em suma, os zoológicos da atualidade mudaram não só na sua estrutura, mas também filosoficamente, respondendo às pressões ambientais e as mudanças dos valores culturais. 


\section{Material e métodos}

O presente trabalho foi realizado a partir de revisão bibliográfica referente a trabalhos que indicassem a importância dos jardins zoológicos para a conservação das espécies, assim como para suas outras funções primordiais, como a importância científica, técnicas de conservação (In Situ/Ex situ), enriquecimento ambiental, reabilitação e soltura dos animais e suas consequências sobre a manutenção ou recuperação destas espécies. Procurou-se a maior profundidade de dados, o que levou a consulta de artigos, teses e dissertações. Tais pesquisas foram realizadas nas bases dos seguintes dados bibliográficos: Google Academico, Scielo e PUBVET. Não foram citados trabalhos provenientes de fontes não reconhecidas pela ciência, tais como blogs ou outras páginas da internet.

\section{Importância dos zoológicos}

O zoológico por muito tempo foi um espaço que continha animais expostos para entreter os visitantes, mas hoje o propósito da instituição é outro, que vai além do entretenimento e inclui pesquisa científica, conservação e educação, estes foram os quatro principais papéis estabelecidos pela legislação brasileira dada pela Instrução Normativa do IBAMA 169 de 2008, que institui zoológicos como categoria de uso e manejo da fauna silvestre em cativeiro. Assim muito zoológicos vem se tornando grandes centros de conservação, trabalhando não apenas para preservar determinada espécie em cativeiro (conservação ex situ), mas também habitats naturais (conservação in situ). Grande parte destes animais são vítimas das caças predatórias, de tráfico, da criação ilegal, dos circos e de acidentes, como atropelamento e queimaduras, quando estes animais são resgatados pela instituição, uma equipe especializada trabalha na reabilitação destes animais e mesmo na sua reintrodução na natureza quando foi possível. Os que não conseguem voltar para natureza ficam na forma eficaz in situ ou em ex situ, muitas vezes servem de estudos para o conhecimento avançado da sua espécie, como o comportamento que tem papel fundamental na conservação biodiversidade, necessidades nutricionais, ambiente, reprodução, fisiologia e genética, com estas informações é possível auxiliar no manejo em cativeiro suprindo todas as suas necessidades e produzindo condições ideias do seu habitat natural, caso seja necessário manter a espécie em ex situ (Artigas \& Fischer, 2019; Singh \& Kaumanns, 2005).

Estes animais ajudam na conservação da sua própria espécie com a genética diversa, que no futuro depois das ameaças presente em seu habitat natural serem diminuídas, possa ser reintroduzidos e voltar ao mais próximo a distribuição natural (McGowan et al., 2017). Com a crise ambiental, as grandes ameaças ao meio ambiente e a redução da biodiversidade, as ações educativas tornam-se importantes na busca pela participação e apoio social à conservação do meio ambiente atuando na sensibilização da população sobre questões ambientais. É nesse contexto que os zoológicos se tornam um espaço em potencial para estimular a formação de hábitos e atitudes positivas em relação à conservação ambiental (Bizerril \& Faria, 2001; Ferreira et al., 2020; Saad et al., 2011).

\section{Importância científica}

Hediger considerou a pesquisa como uma das principais justificativas para a existência de zoológicos e aquários, pois quando essa é adequadamente financiada, o bem-estar dos animais é priorizado (Maple \& Segura, 2015). Um exemplo da importância da pesquisa científica em zoológicos é o trabalho de Burks et al. (2004) que demonstrou a importância de dados empíricos para a decisão correta na introdução de novos elefantes em um grupo, com comparação do modo sequencial e do aleatório. $\mathrm{O}$ sequencial envolvia quatro etapas, com linha de base, contato visual, contato tátil limitado e introdução física, no qual os animais apresentaram comportamento menos agressivo e menores níveis de cortisol (Burks et al., 2004).

Vale ressaltar que os zoológicos atuam também em parceria com os aquários, mediante a Associação de Zoológicos e Aquários do Brasil (AZAB), antiga SZB, que tem por objetivo integrar os zoológicos e aquários brasileiros, contribuindo com o desenvolvimento das instituições e inserindo-as na comunidade internacional, almejando tornar o Brasil um exemplo mundial de conservação ex situ e educação para conservação, através do engajamento em campanhas educacionais. Para isso, a associação tem como missão agregar os Zoológicos e Aquários do Brasil, visando seu desenvolvimento integral, melhoria e fortalecimento. Portanto, para alcançar este compromisso, a AZAB fornece apoio técnico e facilita a cooperação, capacitação, intercâmbio de conhecimentos e a realização de pesquisas nas áreas de manejo, 
educação e conservação, para que as instituições zoológicas brasileiras tenham uma gestão eficiente e trabalhem dentro dos mais altos padrões éticos e de bem-estar animal.

\section{Educação ambiental}

A educação ambiental a partir do zoológico é muito fundamentada pelas escolas, isto porque os conteúdos curriculares referentes à botânica e ecologia são utilizados e enfatizam discussões sobre os ecossistemas brasileiros, adaptações dos seres vivos ao seu ambiente, ecologia urbana, extinção, conservação e preservação das espécies, além de estabelecer uma melhor relação homem-natureza.

As pesquisas referentes à preparação do próprio zoológico deverão centrar-se em estudos dos ecossistemas e das espécies nele contidas, considerando o maior número de aspectos possível como genéticos e etológicos (estudo do comportamento social e individual dos animais em seu habitat natural), sendo dependentes de um trabalho integrado para a conservação. Os meios principais dos zoológicos prestarem educação ambiental são a partir de museus de história natural, área de vegetação nativa, trilhas de interpretação ambiental e produção do próprio material didático, contando com atividades programadas, monitoradas e diferenciadas de acordo com o público frequentador, visitas orientadas, oficinas de arte e ecologia, concursos fotográficos, gincanas e cursos. Os temas são definidos a partir do público-alvo, pois zoológicos para turistas devem ter uma programação diferenciada, com atividade interativas, acesso a multimídia e informações suficientes como placas, folders e informativos para permitir um atrativo turístico e gerar verba, esta que depende, em sua maioria, de prefeituras municipais que são afetadas por novas gestões municipais. De modo positivo, há implantação de programas educativos inéditos e solução de problemas ativos. E em caso negativo, ocorrem mudanças no quadro de funcionários, corte de estagiários e verbas, e alterações na própria administração do zoológico.

A variação entre turistas e a própria comunidade mostra o potencial eclético dos zoológicos, atraindo um público heterogêneo e de visões ecológicas diversas. Esta diferença de ideias também acontece em relação à temas como garimpo, saúde, doenças tropicais, qualidade de vida, participação comunitária, desenvolvimento sustentável, questão indígena, etnobiologia (área que cuida da relação entre sociedades, e as plantas e animais de seu ambiente) e ação antrópica (ações realizadas pelo homem).

Os principais temas apresentados são a divulgação da fauna silvestre, diferenciação da fauna exótica, manejo de fauna e animais peçonhentos, fauna urbana, comportamento, ecologia e evolução. Quando a referência é fauna nativa, os zoológicos dão ênfase no ecossistema em que o zoológico está localizado. Também são divulgados e esclarecidos o trabalho rotineiro dos zoológicos, discutindo os animais em exposição, reprodução e alimentação em cativeiros. Abordando também a poluição, lixo, agrotóxicos, reciclagem, recursos hídricos e minerais, controle biológico, desmatamento, tráfico de animais silvestres, caça e pesca.

\section{Conservação in situ/ex situ}

De acordo com a Resolução No 476 de 8 de junho de 2018, os zoológicos têm permissão para estudar e realizar a conservação de animais da fauna nativa, exótica ou doméstica. Sendo assim, os zoológicos são fundamentais para a conservação, já que por meio da reprodução de espécies ameaçadas é possível se ter um aumento em sua população. As técnicas de conservação não são apenas em cativeiros, sendo possível o manejo da população da espécie ameaçada em seu habitat natural.

O manejo in situ utiliza diferentes metodologias, conforme a espécie. Seu objetivo é possibilitar o crescimento populacional, afastando as ameaças e garantindo o estabelecimento de grupos viáveis. (Moreno et al., 2021). A conservação in situ é realizada dentro do habitat natural da espécie, sendo considerada a melhor estratégia de preservação da fauna. Desde 1992, na Conferência das Nações Unidas sobre o Meio Ambiente e Desenvolvimento, no Rio de Janeiro, a conservação in situ foi designada como prioridade legal e institucional, sendo central para a proteção da biodiversidade global (Pizzutto, 2007).

O Zoológico de São Paulo, em parceria com o Departamento de Pesquisas Aplicadas, fundou em 2015 o NAIS (Núcleo de Atividades In situ). Este tem como foco principal intensificar as pesquisas e atividades de conservação in situ da fauna silvestre brasileira. 
Em situações em que a técnica in situ não é eficaz, por exemplo quando a demanda populacional é muito baixa comparada a área onde a espécie vive; quando a região está destruída, por ações humanas ou naturais, ou desprotegida de leis de preservação ambiental, é preferível a técnica ex situ, onde a conservação da espécie é realizada em cativeiro (zoológicos, aquários ou santuários).

As espécies que são realocadas em cativeiros para ser realizado o manejo de conservação são colocadas em exposição para o público como forma de entretenimento e diversão, a fim de arrecadar verba para manter as atividades da principal missão do zoológico: a conservação (Ricci et al., 2018). A manutenção das espécies em cativeiro envolve muitas pesquisas e cuidados com o manejo dos animais e dos protocolos de reprodução, levando a custos mais elevados se comparados com o in situ, portanto antes da realocação dos animais para cativeiros, é necessário que os mesmos e seus habitats sejam estudados e avaliados, para que a escolha da melhor técnica possa ser baseada não apenas na relação de custo x benefício, mas também no melhor para a população da espécie em questão.

A conservação in situ e ex situ, quando integradas, complementam uma à outra, de forma que, quando aliados a programas de reintrodução, indivíduos de populações ex situ podem ser soltos em seu habitat natural, para auxiliar a conservação in situ (Costa \& Martins, 2008). Portanto, é correto afirmar que a conservação in situ e ex situ realizada pelos zoológicos é muito necessária, visto que a armazenagem de materiais genéticos e os manejos reprodutivos e ambientais são técnicas fundamentais para evitar a extinção das espécies. Todavia, antigamente muitas não faziam parte das atividades de conservação de zoológicos e aquários e o principal motivo disso é a falta de interesse por parte das instituições na realização de pesquisas e preservação das espécies, apresentando como principal foco o entretenimento, assim essas espécies acabavam por ser extintas, ou quase extintas.

A Coruja sorridente (Sceloglaux albifacies), Vison Marinho (Neovison macrodon), Morcego da Ilha Christmas (Pipistrellus murrayi), Caburé de Pernambuco (Glaucidium mooreorum), estes são alguns exemplos dentre mais de 21 mil espécies que foram extintas por falta de atividades de conservação e pesquisas sobre seu habitat natural. Espécies como Ararinha-Azul (Cyanopsitta spixii), RinoceronteNegro-Oriental (Diceros bicornis), Mico Leão Preto (Leontopithecus chrysopygus) foram consideradas extintas; porém, ao acharem alguns exemplares de suas espécies o zoológico conseguiu iniciar suas atividades de conservação. As espécies continuam criticamente em perigo de extinção, mas apresentam menos chances de desaparecer da fauna.

\section{Espécies preservadas pela técnica $e x$ situ}

\section{Arara-Azul-de-Lear (Anodorhynchus leari)}

Normalmente encontrada na Caatinga Baiana, no NE da Bahia, a Arara-Azul-de-Lear é uma das espécies mais conhecidas pelas pessoas por estar na Lista Vermelha da União Internacional para a Conservação da Natureza (IUCN) e do Instituto Chico Mendes de Conservação da Biodiversidade (ICMBio) como em perigo de extinção, visto que antigamente seu posicionamento era ainda mais crítico (Sick et al., 1986). Sua classificação é consequência das perdas de habitat por desmatamento e queimadas, pela caça e principalmente pelo contrabando de animais silvestres.

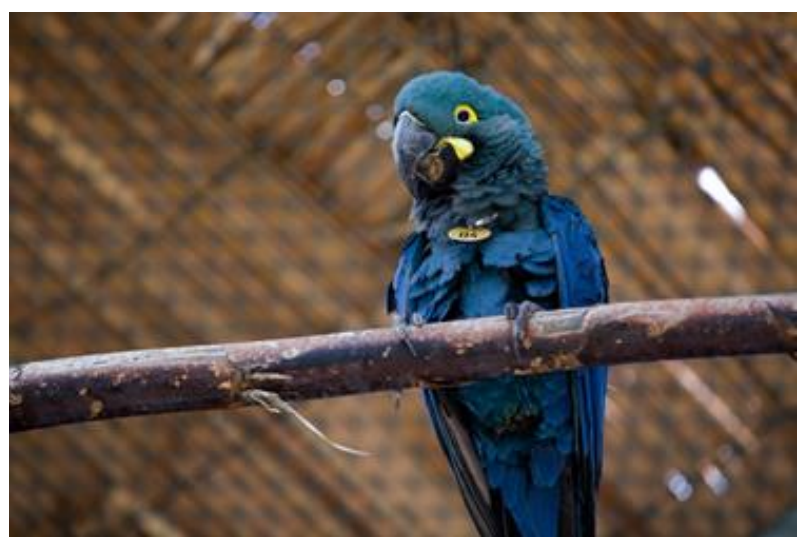

Figura 1. Exemplo de Arara-azul-de-lear em cativeiro. Fonte: Brandt (2019). 
Mantida em cativeiro para manejo de conservação ex situ, começou a apresentar resultados em 2015, quando se teve o primeiro nascimento em cativeiro de uma Arara-Azul-de-Lear, no Zoológico de São Paulo. Esta que acabou se tornando uma das principais instituições de conservação de animais a ter sucesso no manejo reprodutivo da espécie.

Em 2017, foi estabelecido em uma reunião do ICMBio com o Cemave sobre o Plano Nacional para Conservação das Aves da Caatinga (PAN Aves da Caatinga), que inclui o Plano de Cativeiro da AraraAzul-de-Lear, os principais objetivos do PAN, que seriam reduzir a perda e alteração de ambientes naturais, a pressão de caça e do tráfico, visando a manutenção ou recuperação das populações e habitats das espécies, nos próximos cinco anos (ICMBio, 2017). O Zoológico de São Paulo em parceria com o Cemave e com o ICMBio, pretende não apenas aumentar o número de exemplares da espécie, mas mantê-los com saúde e com manejo ideal para conseguir ser realizado a reintrodução destes animais de volta à natureza, na região do Parque Nacional Boqueirão da Onça (BA).

\section{Mico Leão Preto (Leontopithecus chrysopygus)}

Uma das espécies de primatas mais raras do mundo, antigamente foi considerada extinta, mas hoje em dia se encontra criticamente ameaçada de extinção de acordo com o Livro Vermelho do ICMBio (Chiarello et al., 2008; Machado et al., 2008). Espécie nativa da Mata Atlântica, principalmente do interior de São Paulo, tem como principais causas de extinção a caça ilegal, a perda de seu habitat natural e acidentes com os animais que acabam por vir para a cidade.

Em 2014, o Mico Leão Preto foi declarado como Patrimônio Ambiental do estado de São Paulo, tornando o trabalho de conservação realizado pelo Zoológico de São Paulo mais conhecido. O Mico Leão Preto não utiliza apenas uma das técnicas de conservação oferecidas pelas instituições, o zoológico realiza o trabalho de conservação tanto ex situ, quanto em in situ. Isto acontece devido à dificuldade da espécie de se reproduzir, mantendo sua população muito pequena e em estado de preocupação em cativeiros (Rezende, 2016).

O Zoológico de São Paulo realiza o manejo in situ da espécie na região da Floresta Nacional do Capão Redondo, no interior de São Paulo, uma das poucas regiões onde é possível achar exemplares da espécie. As pesquisas in situ são realizadas em parceria com a Universidade Federal de São Carlos e o Instituto de Pesquisas Ecológicas (Zoológico de SP).

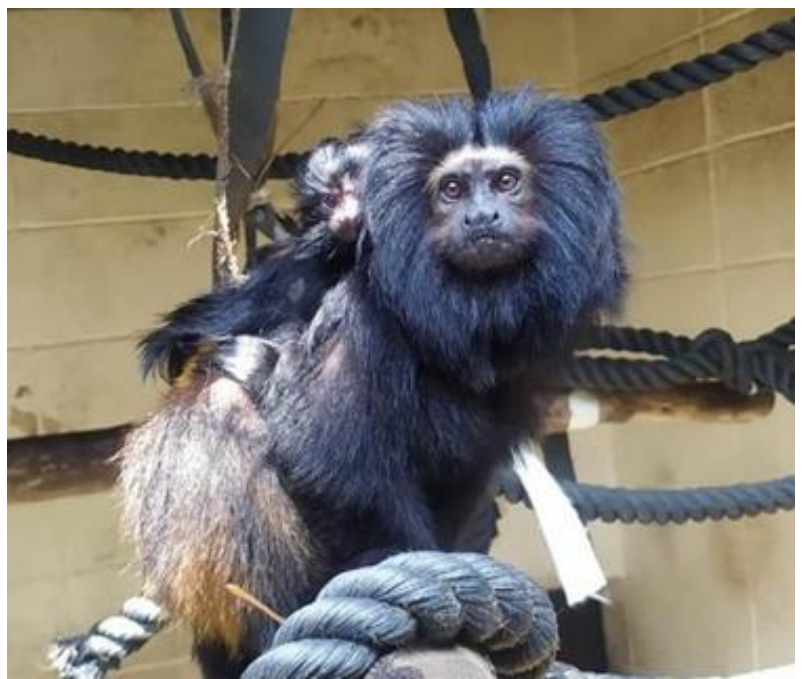

Figura 2. Exemplo de Mico-leão-preto com dois filhotes na Fundação Zoológico de São Paulo. Fonte: Macagnan, (2020).

\section{Pato Mergulhão (Mergus octosetaceus)}

Considerado como uma das aves mais ameaçadas da América do Sul e como criticamente em perigo pelo Livro Vermelho do ICMBio (Chiarello et al., 2008; Machado et al., 2008), o Pato mergulhão conta com um Plano de Ação Nacional do Pato Mergulhão (PAN Pato Mergulhão), fundado pelo IBAMA, em 2006. Os principais motivos para sua extinção são a caça excessiva, a destruição de seus habitats 
naturais e a introdução de espécies exóticas (superiores na cadeia alimentar, ou que transmitem doenças e acabam por diminuir a população da espécie).

Antigamente podia ser encontrado em diversos países da América do Sul, como Brasil, Argentina e Paraguai; porém, com a diminuição de sua população é possível encontrá-lo apenas em algumas regiões brasileiras como, por exemplo, na Serra da Canastra em Minas Gerais, em Goiás e em Tocantins.

O Zooparque de Itatiba é uma das poucas fundações que realizam o manejo de conservação da espécie, devido a isso, em 2011 foi fundado pelo zoológico o Projeto Pato Mergulhão, que tem como foco o manejo de reprodução Ex situ, aumentando a demanda populacional da espécie, para depois reintroduzi-los na natureza. A partir do Projeto Pato Mergulhão é possível afirmar que o Zooparque de Itatiba conta com mais de 40 patos da espécie, visto que apenas em 2020 comemoraram o nascimento de 15 filhotes.

Em parceria com diversos integrantes da PAN Pato Mergulhão, o Zooparque planeja os próximos passos da conservação dos patos: Ampliação da variabilidade genética e o estabelecimento de novos protocolos de manejo para prepará-los para a reintrodução na natureza, e realiza buscas e pesquisas de locais seguros para ser feito a soltura dos animais. (Zooparque de Itatiba).

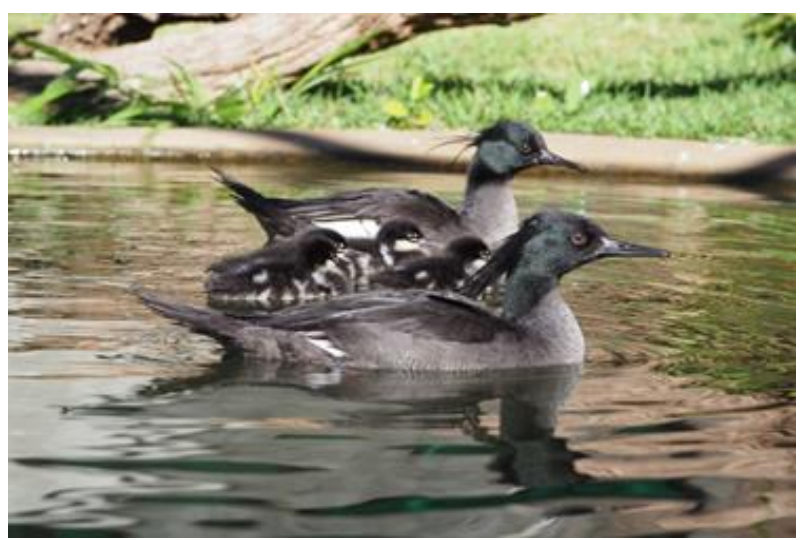

Figura 3. Pato-mergulhão no zoo de Itatiba. Fonte: Zooparque de Itatiba/Divulgação (2018).

\section{Espécies preservadas pela técnica In Situ}

Macaco Bugio-Ruivo (Alouatta guariba clamitans)

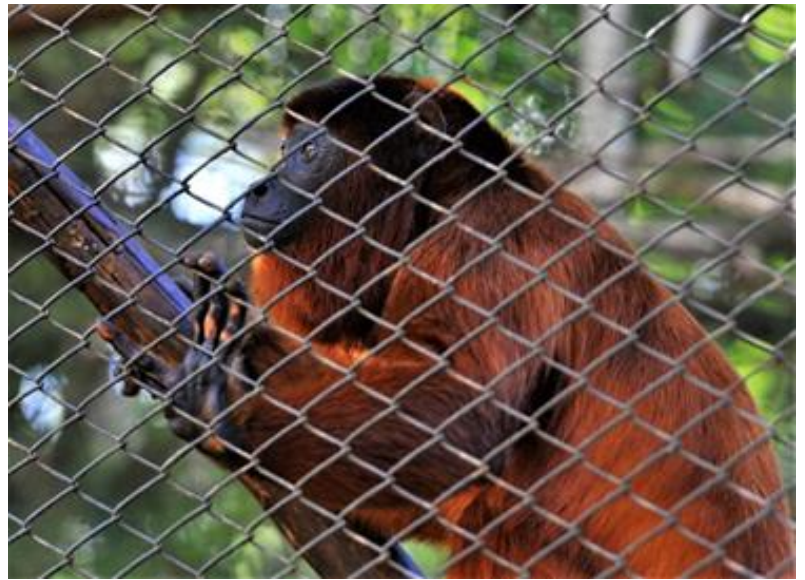

Figura 4. Exemplo de macaco bugio-ruivo no zoológico de Brasília. Fonte: Pinheiro (2021).

Nativos da região da Mata Atlântica, principalmente na linha do Rio Grande do Sul até o Espírito Santo. É considerado como vulnerável pelo Livro Vermelho do ICMBio (Machado et al., 2008), apresentando como principais ameaças a perda de seu habitat, a caça e a violência humana, sua vulnerabilidade ao vírus da febre amarela, quedas e choques elétricos. 
Em 2012, o Zoológico de São Paulo iniciou o manejo de conservação da espécie por meio da técnica In situ, utilizando estudos e pesquisas sobre seu habitat natural, sobre as ameaças de extinção e sobre a espécie, conseguindo trazer melhorias na saúde dos animais e no habitat (como por exemplo a instalações de pontes para evitarem as ruas, troca da fiação elétrica, entre outros), prevenindo muitas mortes por atropelamentos, febre amarela e ataques humanos.

\section{Preguiça-Comum (Bradypus variegatus)}

É possível encontrar exemplares da espécie pelo país, mas principalmente na região Norte, na Mata Atlântica. A Preguiça-Comum se mantém fora de perigo de extinção por não ser comumente caçada, porém o tráfico ilegal e a perda de seu habitat pela ação humana continuam agindo para levar a espécie a extinção.

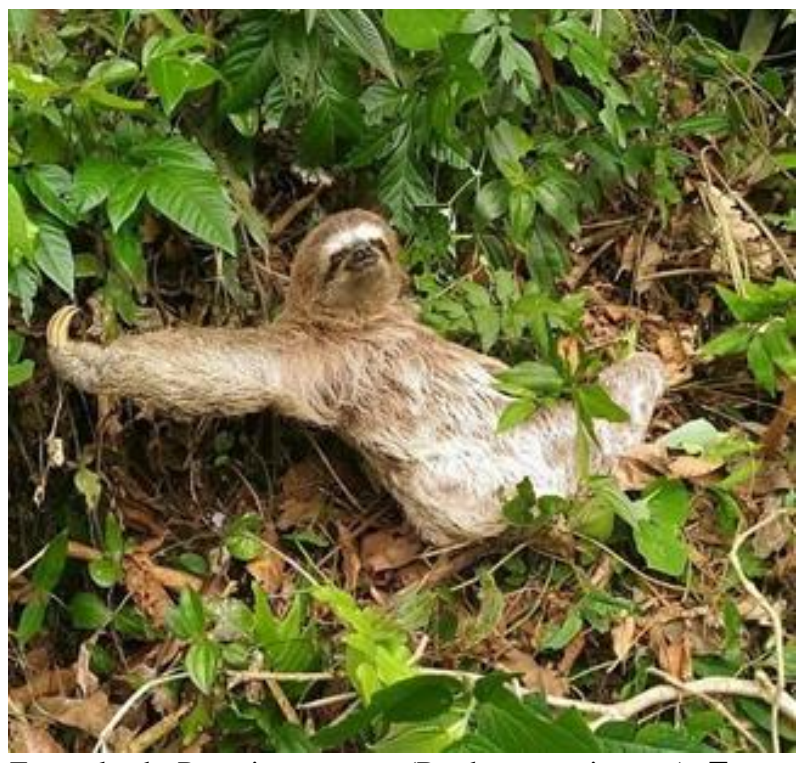

Figura 5. Exemplo de Preguiça comum (Bradypus variegatus). Fonte: Silva, (2021)

Devido a esse fato e ao baixo conhecimento sobre a espécie, o Zoológico de São Paulo, em parceria com o Parque Estadual das Fontes do Ipiranga (PEFI), fundou o Programa Bradypus. Um programa de conservação in situ da espécie, focado na realização de pesquisas e armazenagem de dados, portanto é correto afirmar que a conservação realizada hoje em dia da espécie é uma ação preventiva.

\section{Reabilitação}

Reabilitação é um procedimento que tem como objetivo recuperar as habilidades necessárias para o retorno do animal à vida livre. Para isso, o ideal é fornecer alimentos que as espécies utilizam na natureza, preferencialmente de acordo com a sua disponibilidade sazonal. Esse processo demanda recintos de grandes dimensões para a recuperação das condições musculares e cardiovasculares, por meio da atividade física desses animais.

Dentre os aspectos comportamentais observados que possibilitam avaliar a capacidade da espécie para sobreviver no seu ambiente natural, pode-se dizer que os mais importantes são: tolerância à presença humana, capacidade de obtenção de alimento "natural" e displays de fuga e caça. Animais com baixa tolerância à presença humana, elevado sucesso na obtenção de alimento como localização e captura de presas vivas e bons reflexos de caça e fuga são potenciais candidatos à soltura.

\section{Soltura}

Inicialmente, os veterinários e biólogos avaliam as condições físicas e comportamentais do animal com a finalidade de averiguar se ele está apto para retornar à vida livre, ou ainda, será encaminhado para zoológicos, criadouros registrados no IBAMA ou aos centros de pesquisa. Esses indivíduos, quando prontos, devem passar por processos de reabilitação e adequação alimentar. 
De acordo com Kleiman et al. (2004), a soltura vem a ser o retorno de um espécime à natureza após alguma fatalidade, como atropelamento, tentativa de caça, apreensão, entre outras. Antes de retornarem ao seu habitat natural, tais animais devem passar por um período de quarentena a fim de evitar a transmissão de doenças e avaliar a sua condição física e psicológica, assegurando a sua total recuperação. Após isso é que segue a reintrodução, definida como o restabelecimento de uma espécie em uma área onde historicamente ela existia, mas aonde veio a ser extinta.

A reintrodução requer uma valiosa pesquisa e pode ser realizada por animais criados em cativeiro, porém não é a melhor estratégia para conservar as espécies raras ou em perigo de extinção (Chivers, 1991; Kleiman et al., 2004). Entre os papéis dessa reinserção, destacam-se: aumentar o tempo de sobrevivência das espécies; restabelecer espécies-chave; aumentar o montante da biodiversidade; e buscar o equilíbrio ambiental acima de tudo (Draft Guidelines for Re-introductions, IUCN/SSC Reintroduction Specialist Group). Além disso, nenhum animal deverá retornar à natureza sem que um programa de acompanhamento seja realizado. Sempre que possível o animal deverá ser monitorado e acompanhado até que aconteça sua total reintegração ao ambiente.

Lembrando que dessa etapa fazem parte somente os animais saudáveis e que foram submetidos por um desempenho de reabilitação anteriormente. Atenção especial deve ser dada às doenças infecciosas e parasitárias, levando-se em consideração a possibilidade de se introduzir uma doença nova no ambiente, que possa atingir espécies selvagens nativas e/ou domésticas existentes na área de soltura, além da possível transmissão de doenças de animais domésticos para o exemplar solto (Daszak et al., 2000; Dias, 2003).

Quanto aos ambientes destinados à soltura, podem ser em áreas de ocorrência natural, atual ou histórica, sendo que, nesse caso, o motivo da extinção da espécie deverá ser conhecido e eliminado, tendo que verificar se a inclusão do animal no novo ambiente natural não afetará o equilíbrio do ecossistema e se ele terá chances de sobrevivência à longo prazo, podendo procriar no local, que pode ser também uma Unidade de Conservação.

\section{Considerações finais}

As instituições que mantem animais em cativeiro possuem um compromisso de promover atividades de conservação em espécies ameaçadas de extinção e de prevenção a todas as outras, garantindo o bemestar dos animais que lá vivem. Os zoológicos e os aquários promovem, através da exposição dos animais para entretenimento, um relacionamento mais humano entre os visitantes e os animais. Além disso, os projetos voltados para proteção ambiental e conservação In situ e Ex situ das espécies são realizadas em conjunto com centros de pesquisa especializados no estudo de animais silvestres, evidenciando a base científica e empírica de suas atividades.

\section{Referências bibliográficas}

Almeida, P. A., Oliveira, J. R., \& Mantovani, M. M. (2010). Determinantes da interação homem-animal. PUBVET, 4(4), 144.

Artigas, N. A. S., \& Fischer, M. L. (2019). Limitações no cativeiro quanto a promoção de bem-estar em primatas na percepção do visitante do Zoológico de Curitiba. Revista Brasileira de Educação Ambiental, 14(1), 49-68.

Bizerril, M., \& Faria, D. S. (2001). Percepção de professores sobre a educação ambiental no ensino fundamental. Revista Brasileira de Estudos Pedagógicos, 82(200-01-02).

Brandt, M. /G1 (2019) https://g1.globo.com/natureza/noticia/2020/02/21/quatro-filhotes-de-araraazulde-lear-em-perigo-de-extincao-nascem-em-zoologico-de-sp.ghtml.

Brasil, (1988). Art. 225 da Constituição da República Federativa do Brasil de 5 de outubro de 1988. Capítulo IV Do Meio Ambiente

Burks, K. D., Mellen, J. D., Miller, G. W., Lehnhardt, J., Weiss, A., Figueredo, A. J., \& Maple, T. L. (2004). Comparison of two introduction methods for African elephants (Loxodonta africana). Zoo Biology, 23(2), 109-126. 
Chiarello, A. G., Aguiar, L. M. S., Cerqueira, R., Melo, F. R., Rodrigues, F. H. G., \& Silva, V. M. F. (2008). Mamíferos ameaçados de extinção no Brasil. Livro Vermelho Da Fauna Brasileira Ameaçada de Extinção, 2, 680-880.

Chivers, D. J. (1991). Species differences in tolerance to environmental change. In Primate responses to environmental change (pp. 5-37). Springer.

Costa, P. M., \& Martins, C. F. (2008). Conservação de recursos genéticos animais através de biotécnicas de reprodução. Universitas: Ciências Da Saúde, 6(1), 39-55.

Daszak, P., Cunningham, A. A., \& Hyatt, A. D. (2000). Emerging infectious diseases of wildlife--threats to biodiversity and human health. Science, 287(5452), 443-449. https://doi.org/10.1126/science.287.5452.443.

Dias, J. L. C. (2003). Zoológicos e a pesquisa científica. São Paulo: Biológico, 65(1), 127-128.

Ferreira, A. S., Belato, B. C. A., Silva, D. A., Santos, J. R. C., Correa, T. H. C., Gonçalves, E. S., Leira, M. H., \& Guedes, E. (2020). Bem-estar animal no zoológico: estudo de caso do zoológico de Varginha - Parque Zoobotânico Dr. Mario Frota. Revista Agroveterinária Do Sul de Minas, 2(1), 1-9.

Francis da Silva L. / Cachoeiras de Macacu, RJ https://animalbusiness.com.br/colunas/animaissilvestres/preguica-comumbradypus-variegatus/ -

ICMBio -Instituto Chico Mendes de Conservação da Biodiversidade (2017). O Centro Nacional de Pesquisa e Conservação de Aves Silvestres avança na proteção das aves da caatinga.Disponível em <https://www.icmbio.gov.br/portal/ultimas-noticias/20-geral/9005-cemave-avanca-na-protecaodas-aves-da-caatinga > . Acesso em: 05 nov. 2021

IUDZG - International Union of Directors of Zoological Gardens / International Union of The Conservation of Nature Species Survival Comission. (1993). The world zoo conservation strategy: the role of the zoo and aquaria of the world in global conservation. Illinois, Chicago Zoological Society.

Kleiman, D. G., Geist, V., \& McDade, M. C. (2004). Grzimek's animal life encyclopedia.

Lei no 9.795/99, Art. 225 da Constituição da República Federativa do Brasil de 5 de outubro de 1988. http://www.planalto.gov.br/ccivil_03/leis/19795.htm

Macagnan, A. M/Zoo SP (2020), https://g1.globo.com/sp/sao-paulo/noticia/2020/09/10/ameacadosdeextincao-dois-filhotes-de-mico-leao-preto-nascem-no-zoologico-de-sp.ghtml

Machado, A. B. M., Drummond, G. M., \& Paglia, A. P. (2008). Livro vermelho da fauna brasileira ameaçada de extinção. In Livro vermelho da fauna brasileira ameaçada de extinção (p. 1420).

Maple, T. L., \& Segura, V. D. (2015). Advancing behavior analysis in zoos and aquariums. The Behavior Analyst, 38(1), 77-91.

Marino, L. M. R. (2008). Caracterização e zoneamento ambiental do zoológico municipal de Mogi Mirim-SP. Universidade Federal de São Carlos.

Maués, E., \& Maline, C. (2019). O zoológico como questão sociocientífica. Revista Brasileira de Educação Básica, 4(15), 1-8.

McGowan, P. J. K., Traylor-Holzer, K., \& Leus, K. (2017). IUCN guidelines for determining when and how ex situ management should be used in species conservation. Conservation Letters, 10(3), 361-366.

Moreno, D. H. H., Isabel, M. I. S. T., Feltrin, F. H., \& Martins, C. (2021). A sensibilização socioambiental para conservação e preservação da biodiversidade sob a perspectiva dos visitantes dos parques das aves. Orbis Latina, 11(1), 86-107.

$\begin{array}{lllll}\text { Normativa } & \text { do } & 169 & \text { IBAMA }\end{array}$ https://www.ibama.gov.br/component/legislacao/?view=legislacao\&legislacao $=113878$

Pinheiro, A. (2021). Agência Brasília. https://www.agenciabrasilia.df.gov.br/2021/04/25/de-a-a-z-temnome-paratodo-gosto-no-zoologico-de-brasilia/ - Foto: Acácio Pinheiro / Agência Brasília

Pizzutto, C. S. (2007). Condicionamento em animais de zoológico. Boletim Técnico ABRAVAS, 1(8), 1-10.

Resolução $\mathrm{N}^{\circ} 476$ de 8 de junho de 2018 https://www.in.gov.br/materia//asset_publisher/Kujrw0TZC2Mb/content/id/26171778/do1-2018-06-18-resolucao-n476-de-8-dejunho-de-2018-26171713 8. 
Rezende, G. C. (2016). Mico-leão-preto: a história de sucesso na conservação de uma espécie ameaçada. Matrix Editora.

Ricci, G. Dela, Branco, C. H., Sousa, R. T., \& Titto, C. G. (2018). Efeito de diferentes técnicas de enriquecimento ambiental em cativeiro de onças suçuaranas (Puma concolor). Ciência Animal Brasileira, 19(e-47693, 2018), 1-10. https://doi.org/10.1590/1809-6891v19e-47693.

Saad, C. E. P., Saad, F. M. de O. B., \& França, J. (2011). Bem-estar em animais de zoológicos. Revista Brasileira Biociências, 40, 38-43.

Sanjad, N., Oren, D. C., Silva Junior, J. S., Hoogmoed, M. S., \& Higuchi, H. (2012). Documentos para a história do mais antigo jardim zoológico do Brasil: o parque zoobotânico do Museu Goeldi. Boletim Do Museu Paraense Emílio Goeldi. Ciências Humanas, 7, 197-258.

Sick, H., Gonzaga, L. P., \& Teixeira, D. M. (1986). A arara-azul-de-Lear, Anodorhynchus leari Bonaparte, 1856. Revista Brasileira de Zoologia, 3, 441-463.

Singh, M., \& Kaumanns, W. (2005). Behavioural studies: A necessity for wildlife management. Current Science, 1230-1236.

Histórico do artigo:

Recebido: 22 de agosto de 2021

Aprovado: 26 de setembro de 2021

Disponível on-line: 30 de novembrode 2021
Licenciamento: Este artigo é publicado na modalidade Acesso Aberto sob a licença Creative Commons Atribuição 4.0 (CC-BY 4.0), a qual permite uso irrestrito, distribuição, reprodução em qualquer meio, desde que o autor e a fonte sejam devidamente creditados. 